\title{
Produção de salgadinho extrusado de quirera de arroz para uso na indústria de alimentos
}

\author{
Extruded snack broken rice production to the food industry usage

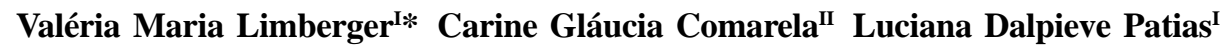 \\ Fabrício Barros Brum ${ }^{I}$ Tatiana Emanuelli ${ }^{I I}$ Leila Picolli da Silva ${ }^{\text {III }}$
}

\section{RESUMO}

O Brasil é o principal produtor de arroz fora do continente asiático. Durante seu beneficiamento, são gerados em média $14 \%$ de quirera, representando perda econômica para o setor arrozeiro do país. Porém, esse resíduo tem enorme potencial para ser utilizado na indústria alimentícia. Assim, o objetivo deste trabalho foi avaliar a aplicabilidade da quirera de arroz na produção de salgadinho extrusado. O salgadinho de quirera de arroz foi avaliado sensorialmente, através de testes de aceitabilidade e intenção de compra, e quimicamente, através da composição centesimal. O salgadinho extrusado de quirera de arroz sabor queijo apresentou boa aceitabilidade, apesar de perda nos escores de aparência e cor, quando comparado ao salgadinho extrusado de milho elaborado pela mesma empresa. Os salgadinhos extrusados demonstraram menor teor de umidade, mesmo teor de proteína e maior teor de cinza, lipídios e fibras, quando comparados à quirera de arroz nativa. As alterações promovidas na quirera de arroz pela extrusão possibilitam sua aplicação comercial.

Palavras-chave: quirera de arroz, extrusão, salgadinho, aceitabilidade.

\section{ABSTRACT}

Brazil is the main producer of rice outside the Asiatic continent. During the manufacturing, about $14 \%$ of broken rice are generated, which represents economic loss for the country's rice industry. Nevertheless, this residual product has enormous potential for using in food industry. The aim of the study was to evaluate the applicability of broken rice in the extruded snack formulation. The snack was sensory evaluated by testing acceptability and purchase intent, and chemically, by centesimal composition. The snacks of broken rice cheese flavor showed good sensorial acceptability, in spite of the loss in appearance and color scores when compared to the corn ones prepared by the same company. The extruded snacks showed lower moisture content, equal levels of protein and higher levels of ash, fat and fiber when compared to native broken rice. The changes promoted in broken rice by extrusion made possible its commercial application.

Key words: broken rice, extrusion, snacks, acceptability.

\section{INTRODUÇÃO}

O Brasil é o principal produtor de arroz fora do continente asiático, com mais de 12 milhões de toneladas produzidas na safra de 2007/2008 (IBGE, 2009). Durante seu beneficiamento, são produzidos em média $14 \%$ de grãos quebrados. O valor deste subproduto, classificado como quirera, é a quinta parte do obtido na comercialização do grão inteiro, pois é rejeitado para consumo humano, o que representa um problema econômico para a indústria arrozeira. No entanto, esse subproduto é uma fonte rica em amido (COFFMAN \& JULIANO, 1987), podendo ser explorada de forma eficiente na indústria de alimentos.

Os chamados alimentos de conveniência estão em crescimento no mundo inteiro. No Brasil, a produção de salgadinhos extrusados está ganhando importância, e o potencial de crescimento do mercado é promissor (ZELAYA, 2000). Muitas vantagens têm sido atribuídas à extrusão, como baixo custo, alta produtividade, versatilidade e produto uniforme.

IPrograma de Pós-graduação em Ciência e Tecnologia de Alimentos, Centro de Ciências Rurais (CCR), Universidade Federal de Santa Maria (UFSM), 97105-900, Santa Maria, RS, Brasil. E-mail: vlimberger@yahoo.com.br. *Autor para correspondência. IINúcleo Integrado de Desenvolvimento em Análises Laboratoriais (NIDAL), Departamento de Tecnologia e Ciência dos Alimentos, CCR, UFSM, Santa Maria, RS, Brasil.

IIIDepartamento de Zootecnia, CCR, UFSM, Santa Maria, RS, Brasil. 
A estrutura dos produtos extrusados depende, principalmente, da gelatinização do amido e da subsequente expansão do vapor de água, o que origina a queda de pressão na saída do material pela matriz extrusora, resultando em um produto leve e crocante(BOONYASIRIKOOL \& CHARUNUCH, 2000). Dependendo do produto pretendido, diferentes temperaturas, umidade, velocidade de cisalhamento e tipo de parafuso podem ser utilizados (FARAJ et al., 2004).

Durante o processo de extrusão, ocorrem alterações na matéria-prima, como gelatinização do amido, desnaturação de proteínas, (in)ativação enzimática, reações de Maillard (CHUANG \& YEH, 2004), formação de complexo entre amilose e lipídios e reações de degradação de vitaminas e pigmentos (ILO et al., 1999).

Salgadinhos extrusados possuem uma variedade de forma, textura e sabor, e a aceitabilidade desse tipo de produto está diretamente relacionada a tais características sensoriais. Em geral, os salgadinhos são produzidos com milho quebrado, enquanto o uso da quirera de arroz é relativamente raro (BOONYASIRIKOOL \& CHARUNUCH, 2000). Visando à utilização e à agregação de valor à quirera de arroz, este trabalho foi conduzido com o objetivo de avaliar a aplicabilidade desse subproduto na produção de salgadinhos extrusados.

\section{MATERIAL E MÉTODOS}

A quirera de arroz foi cedida por dois moinhos de Santa Maria, RS (Berleze e Cia. Ltda. e Favarin e Cia.). A extrusão foi realizada na empresa "OK Alimentos” (Ijuí, RS), utilizando-se extrusor de alta compressão, projetado e fabricado pela própria empresa, dotado de rosca simples, com cilindro e rosca sem-fim curtos, operando nas mesmas condições de processo utilizadas pela indústria para a produção de salgadinho extrusado de milho, à temperatura de $112 \pm 1^{\circ} \mathrm{C}$ e à rotação de $480 \mathrm{rpm}$.

O salgadinho foi produzido utilizandose $100 \%$ de quirera de arroz. A quirera de arroz foi condicionada a $14 \%$ de umidade, adicionada de $2 \mathrm{~mL}$ de solução 0,25\% de corante natural de urucum (Bixa orellana) para cada kg de matéria-prima, sendo a massa introduzida no alimentador do extrusor. O diâmetro de abertura da matriz ( $3 \mathrm{~mm}$ ) e a velocidade do sistema de corte determinaram a produção de pellets de aproximadamente $3,5 \mathrm{~cm}$ de comprimento por $1 \mathrm{~cm}$ de diâmetro. Após a extrusão, as amostras passaram por secador rotatório para reduzir a umidade do produto até $5 \%$. Nessa etapa, o flavorizante foi adicionado por aspersão [15g kg-1 de sal, 8,3g $\mathrm{kg}^{-1}$ de aroma sabor queijo (Duas Rodas Ind., Jaraguá do Sul, SC, Brasil) dissolvidos em 45,7 $\mathrm{mL} \mathrm{kg}^{-1}$ de gordura de algodão hidrogenada (Grupo Maeda, Itumbiara, GO, Brasil)]. Os salgadinhos foram acondicionados em sacos plásticos, em porções de 50g, para posterior realização das análises.

Para avaliar sensorialmente os salgadinhos de quirera de arroz, foi utilizado teste de aceitabilidade global com 176 provadores não treinados, através de método afetivo segundo a Associação Brasileira de Normas Técnicas (ABNT, 1993; ABNT, 1998), utilizando-se escala hedônica de cinco pontos [desgostei muito (1), desgostei (2), indiferente (3), gostei (4) e gostei muito (5)]. Os mesmos provadores foram questionados quanto à intenção de compra do produto.

Além da aceitabilidade global, outros 30 provadores não treinados avaliaram cada atributo do produto obtido a partir da quirera de arroz e do produto elaborado com milho pela mesma empresa. Os atributos de aparência, cor, odor, sabor e textura foram avaliados em ambos os produtos ao mesmo tempo, por método afetivo segundo a Associação Brasileira de Normas Técnicas (ABNT, 1993; ABNT, 1998), utilizando-se escala hedônica de sete pontos [desgostei muitíssimo (1), desgostei muito (2), desgostei (3), indiferente (4), gostei (5), gostei muito (6) e gostei muitíssimo (7)].

Umidade, cinzas, proteína bruta e fibra (total, solúvel e insolúvel) foram determinadas de acordo com a metodologia oficial da Association of Official Analytical Chemists (AOAC, 1995). Para análise de fibra, foram utilizadas as enzimas Termamyl $120 \mathrm{~L}^{\circledR}$, Flavourzyme 500L ${ }^{\circledR}$ eAMG 300L ${ }^{\circledR}$, da Novozymes Latin American Limited. A determinação de amido foi realizada de acordo com o método da Association of Official Analytical Chemists (AOAC, 1995) modificado por WALTER (2005), utilizando-se as enzimas Termamyl $120 \mathrm{~L}^{\circledR}$ (pH 6,8 a $95^{\circ} \mathrm{C}$ por 5 minutos), Flavourzyme 500L ${ }^{\circledR}$ (pH 6,8 a $60^{\circ} \mathrm{C}$ por 30 minutos) e AMG 300L ${ }^{\circledR}(\mathrm{pH} 4,5$ a $50^{\circ} \mathrm{C}$ por 30 minutos), tendo a absorbância das amostras sido lida em espectrofotômetro a $505 \mathrm{~nm}$. O teor de gordura foi determinado gravimetricamente pelo método de BLIGH \& DYER (1959), utilizando-se clorofórmio, metanol e água como solventes. Para o cálculo do valor calórico, foram utilizados os fatores de conversão de Atwater, ou seja, 9 calorias/ grama-1 para lipídios, 4 calorias grama ${ }^{-1}$ para carboidratos e 4 calorias grama ${ }^{-1}$ para proteínas (SBD, 2009). Com exceção das análises sensoriais, todas as análises foram realizadas na quirera de arroz nativa (não extrusada), no salgadinho extrusado obtido a partir da quirera de arroz e no salgadinho extrusado elaborado com milho pela mesma empresa, sob as mesmas condições. 
O experimento foi conduzido conforme delineamento inteiramente casualizado, com três repetições e triplicata. Os dados foram submetidos à análise de variância, seguida de teste de Tukey $(\mathrm{P}<0,05)$. A aceitabilidade global do salgadinho foi avaliada por teste não paramétrico $\chi^{2}$ com significância assimptótica $(\mathrm{P}<0,01)$.

\section{RESULTADOS E DISCUSSÃO}

Os resultados da avaliação do salgadinho extrusado de quirera de arroz por 176 provadores demonstraram elevado grau de aceitabilidade global, pois $95 \%$ dos julgadores afirmaram ter gostado muito (52\%) ou gostado (43\%) do produto, enquanto pequena parcela mostrou-se indiferente $(2 \%)$, desgostou (2\%) ou desgostou muito (1\%) do produto (Figura 1). Os resultados não demonstram diferença significativa entre "gostei muito" e "gostei”. Também não diferiram significativamente as opções “indiferente”, “desgostei” e "desgostei muito”. Seguindo a mesma tendência da aceitabilidade, quanto à intenção de compra, $89 \%$ dos provadores responderam que comprariam o produto, sendo que apenas 6\% responderam que não comprariam e 5\% não responderam (Figura 1).

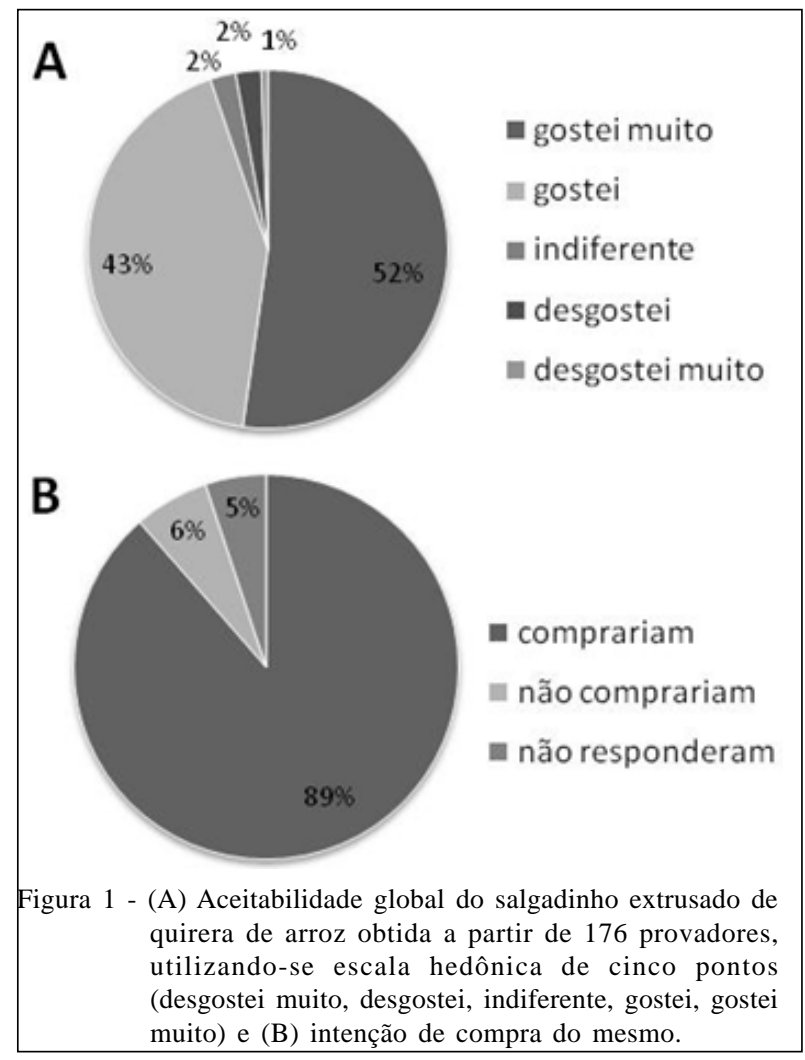

Os resultados da análise sensorial feita por 30 julgadores não treinados para o salgadinho de quirera de arroz e o salgadinho de milho elaborado pela mesma empresa e sob as mesmas condições estão demonstrados na figura 2. Quanto ao odor, ao sabor e à textura, não houve diferença significativa entre os produtos. Com relação à aparência e à cor, os julgadores demonstraram preferência significativa pelo salgadinho extrusado de milho comercial, o que pode ser explicado por este já possuir fabricação padronizada. Porém, essas características sensoriais são os primeiros critérios observados pelo consumidor no momento da compra, sendo decisivos na escolha do produto. Portanto, comercialmente, não basta que os salgadinhos em teste possuam as demais características sensoriais satisfatórias, pois cor e aparência são fundamentais.

Os raios de expansão da quirera de arroz e do milho diferem; por isso, mesmo tendo passado pela matriz extrusora de mesmo diâmetro, esse fator influi de maneira diferenciada sobre a refletância da luz no produto e, consequentemente, sobre sua intensidade de cor.

O salgadinho comercial é elaborado a partir de milho, que contribui para a coloração amarelada, e o do teste, a partir de quirera de arroz, de coloração mais clara, o que justifica a diferença de cor. Porém, a coloração mais clara da quirera de arroz é favorável quando se pretende utilizar outros corantes.

É possível adaptar-se a produção de salgadinho comercial para que seja feito a partir de quirera de arroz ou ainda optar-se por uma substituição parcial de milho por quirera de arroz. BOONYASIRIKOOL \& CHARUNUCH (2000) demonstraram, em seu estudo, redução nos escores sensoriais de salgadinhos para cor ao substituir-se 80\% do milho por quirera de arroz; porém, não encontraram diferença significativa na substituição de 50\%. Nesse mesmo estudo, também não foi constatada diferença significativa para flavor entre o salgadinho de milho e o substituído por $80 \%$ de quirera de arroz, mas a substituição de apenas 50\% demonstrou melhora para essa característica sensorial. Com relação à textura e à aceitação, esses autores encontraram melhora significativa para todos os graus de substituição.

Os resultados demonstram que o processo de fabricação de ambos os salgadinhos causou perda de umidade e aumento significativo no teor de cinza em comparação à quirera nativa. Esse resultado era previsível, pois a extrusão promove perda de água, e a adição de flavorizante contendo cloreto de sódio (sal), o aumento da fração 


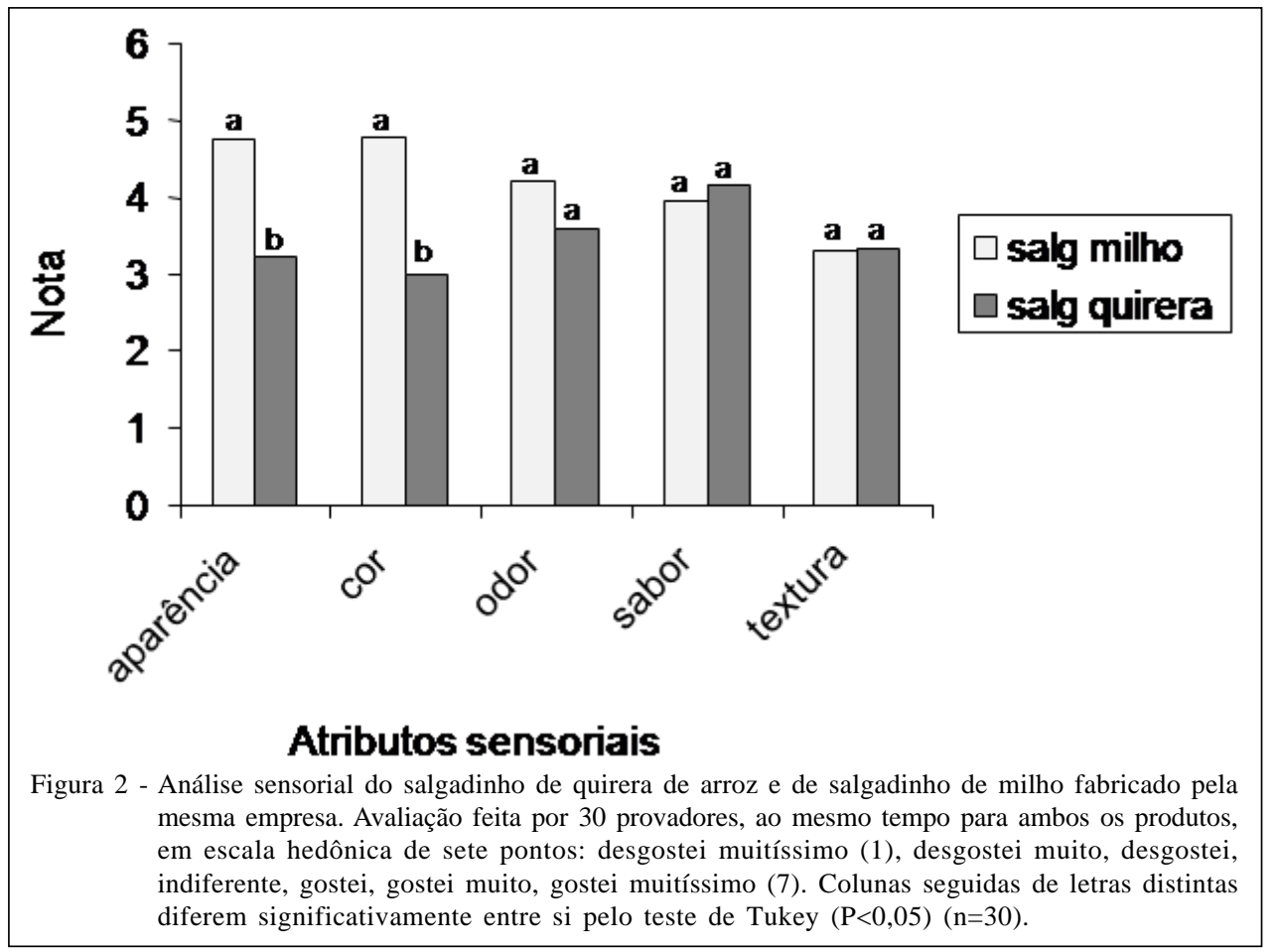

mineral. Os teores de proteína bruta dos salgadinhos de quirera de arroz, salgadinhos comerciais e quirera de arroz nativa não diferiram significativamente (Tabela 1 ).

O processo de fabricação aumentou de forma significativa o teor de gordura do salgadinho de quirera de arroz quando comparado à quirera de arroz nativa, o que pode ser explicado pela adição de gordura vegetal hidrogenada ao mesmo. Isso pode ser comprovado por não haver diferença significativa no teor de gordura entre o salgadinho teste e o comercial, pois o processo de fabricação e o teor de gordura adicionado foram o mesmo.

Os teores de fibra total, solúvel e insolúvel aumentaram com o processo de extrusão (Tabela 1), quando comparados aos da quirera nativa. Comparando-se as amostras de salgadinho de quirera de arroz às amostras comerciais de milho, a primeira apresentou maior teor de fibra solúvel e menor teor de fibra insolúvel; porém, o conteúdo de fibra alimentar total não diferiu.

Alguns mecanismos podem ser sugeridos para se explicar as mudanças no perfil da fibra alimentar da quirera de arroz processada em relação à quirera de arroz nativa. $\mathrm{O}$ aumento na fibra solúvel possivelmente foi devido à solubilização de componentes fibrosos da quirera de arroz em razão das altas temperaturas e da pressão no processo de extrusão. A ocorrência de amido resistente do tipo 3 (RS3) em grãos de produtos processados termicamente foi demostrada por ENGLYST et al. (1983). Esses autores observaram que o amido resistente formado a partir do processamento hidrotérmico de grãos teve propriedades similares às

Tabela 1 - Composição química de quirera de arroz nativa (QAN) e salgadinhos extrusados de quirera de arroz (SQA) e salgadinhos extrusados de milho (SQM).

\begin{tabular}{|c|c|c|c|c|c|c|c|}
\hline Amostra & Umidade & Cinzas & $\begin{array}{c}\text { Proteína } \\
\text { bruta }\end{array}$ & Lipídios & $\begin{array}{l}\text { Fibra alimentar } \\
\text { total }\end{array}$ & $\begin{array}{l}\text { Fibra alimentar } \\
\text { solúvel }\end{array}$ & $\begin{array}{l}\text { Fibra alimentar } \\
\text { insolúvel }\end{array}$ \\
\hline QAN & $10,87 \pm 1,12^{\mathrm{a}}$ & $0,44 \pm 0,03^{b}$ & $8,55 \pm 0,09^{\mathrm{a}}$ & $1,14 \pm 0,08^{b}$ & $2,13 \pm 0,14^{b}$ & $1,78 \pm 0,2^{b}$ & $0,34 \pm 0,13^{c}$ \\
\hline SQA & $5,11 \pm 0,04^{\mathrm{c}}$ & $2,27 \pm 0,03^{\mathrm{a}}$ & $8,58 \pm 0,07^{\mathrm{a}}$ & $8,07 \pm 0,35^{\mathrm{a}}$ & $4,37 \pm 0,42^{\mathrm{a}}$ & $3,21 \pm 0,13^{\mathrm{a}}$ & $1,16 \pm 0,33^{b}$ \\
\hline SQM & $7,23 \pm 0,015^{b}$ & $2,35 \pm 0,001^{\mathrm{a}}$ & $8,47 \pm 0,14^{\mathrm{a}}$ & $8,26 \pm 0,03^{\mathrm{a}}$ & $4,18 \pm 0,13^{\mathrm{a}}$ & $2,15 \pm 0,09^{b}$ & $2,03 \pm 0,05^{\mathrm{a}}$ \\
\hline
\end{tabular}

Valores seguidos de letras distintas na coluna diferem significativamente pelo teste de Tukey $(\mathrm{P}<0,05)$; os resultados são média \pm desvio padrão. 
de fibra alimentar insolúvel, o que pode justificar o aumento do teor desta nos grãos utilizados no estudo. VASANTHAN et al. (2002) também sugeriram que a formação do RS3 deve ter sido responsável pelo aumento do conteúdo de fibra alimentar total e insolúvel em farinha de cevada extrusada.

FORNAL et al. (1987) demonstraram redução no conteúdo de celulose e lignina em farinha extrusada de cevada e trigo-mouro, o que significa que essas sofrem algum tipo de degradação durante o processo, passando de fibra insolúvel para fibra solúvel, o que explica o aumento de fibra solúvel com a extrusão.

O aumento nos teores de fibra é um resultado desejável da extrusão, devido ao aumento do teor de amido resistente, pois permite que o alimento seja comercializado como fonte de fibra (teor maior que $3 \%)$, sendo este um bom apelo comercial, já que os consumidores têm optado por alimentos menos prejudiciais à saúde, e o teor de fibra contribui para isso.

\section{CONCLUSÕES}

O salgadinho produzido a partir da extrusão da quirera de arroz apresentou boa aceitabilidade global. Porém, quando os atributos foram avaliados separadamente, os provadores mostraram preferência pelo salgadinho elaborado com milho quanto aos atributos aparência e cor (mais inflado e amarelo), decisivos no ato da compra. No entanto, tal problema pode ser contornado nos salgadinhos de quirera de arroz através da implementação de adaptações em sua fabricação, como o uso de corantes.

\section{AGRADECIMENTOS}

Os autores agradecem aos moinhos Berleze e Cia. Ltda. e Favarin e Cia. pela doação da amostra; à empresa "OK alimentos”, por permitir a utilização dos equipamentos; e à Coordenação de Aperfeiçoamento de Pessoal de Nível Superior (CAPES), pela concessão de bolsa.

\section{REFERÊNCIAS}

ABNT. Associação Brasileira de Normas Técnicas. Métodos de análise sensorial dos alimentos e bebidas. São Paulo, 1993. 2p. (NBR 12994).

ABNT. Associação Brasileira de Normas Técnicas. Escalas utilizadas em análise sensorial de alimentos e bebidas. São Paulo, 1998. 3p. (NBR 14141).

AOAC. Association of Official Analytical Chemists. Official Methods of Analysis. 16.ed. Washington, $1995 . \quad$ ni.

BLIGH, E.C.; DYER, W.J. A rapid method of total lipid. Extraction and purification. Canadian Journal of Biochemistry and Physiology, v.37, p.911-917, 1959.
BOONYASIRIKOOL, P.; CHARUNUCH, C. Development of corngrit-broken rice based food by extrusion cooking. National Science. v.34, p.279-288, 2000.

CHUANG, G.C.; YEH, A. Effect of screw profile on residence time distribution and starch gelatinization of rice flour during single screw extrusion cooking. Journal of Food Engineering, v.63, p.21-31, 2004. Disponível em: <http://www.sciencedirect.com/ science?_ob=ArticleURL\&_udi=B6T8J -49D6Y 44 $3 \&$ \&user $=687353 \&$ \&doc $=1 \&$ \& fmt $=\&$ \&_orig $=$ search \&_sort $=$ d \&_d oc anchor $=\&$ vi e w $=$ c $\&$ _ a c c t $=$ C 0000378 $82 \& \quad$ version $=1 \&$ url l version $=0 \&$ u s e rid $=687353 \& \mathrm{md} 5=44 \mathrm{~d} 9 \mathrm{~b} 954 \mathrm{~d} 3 \mathrm{f} 378 \mathrm{~b} 950710 \mathrm{a} 7138 \mathrm{~b} 02 \mathrm{cb} \overline{6}>$. Acesso em: 20 jan. 2009. doi:10.1016/s0260-8774(03)00278-4.

COFFMAN, W.R.; JULIANO, B.O. Rice. In: OLSON, R.A.; FREY, K.J. (Ed.). Nutritional quality of cereal grains: genetic and agronomic improvement. Madison: American Society of Agronomy, 1987. Cap.5, p.101-131.

ENGLYST, H. et. al. Starch and non-starch polysaccharides in some cereal foods. Journal of the Science of Food and Agriculture, v.341, p.1434-1440, 1983.

FARAJ, A. et. al. The effect of extrusion cooking on resistant starch formation in waxy and regular barley flours. Food Research International, v.37, p.517-525, 2004. Disponível em: <http:// www.sciencedirect.com/science?_ob=ArticleURL\&_udi=B6T6V4C2NM3Y-3\&_user=687353\&_rdoc $=1 \& \_f m t=\&$ \&orig $=$ search\& s o r t $=$ d \&_d o c a n c h or $=\&$ vi e w $=$ c \&_a c c t $=$ C 00 $0037882 \&$ _ versi o $n=1 \&$ _ur l Vers i o $n=0$ \&_userid=687353\&md5=81991ceb6f4e7fcd94ce3416eef0da5f. Acesso em: 23 nov. 2008. doi:10.1016/j.foodres.2003.09.015.

FORMAL, L. et al. Chemical characteristics and physicochemical properties of the extruded mixtures of cereal starches. Starch/Stärke, v.39, p.75-78, 1987.

IBGE - Instituto Brasileiro de Geografia e estatística. Prognóstico da Produção Agrícola nacional. Acessado em 20 abr. 2009. Online. Disponível em: <http://www.ibge.gov.br/ home/estatistica/indicadores/agropecuaria/lspa/ lspa_200812_9.shtm>.

ILO, S. et. al. Extrusion cooking of rice flour and amaranth blends. Lebensm-Wiss u-Technology, v.32, p.79-88, 1999.

SBD - Sociedade Brasileira de Diabetes. Acessado em 20 jun. 2009. Online. Disponível em: www.diabetes.org.br/ aprendendo/contagem_carboidratos/contcarb01.php\#caloria.

VASANTHAN, T. et al. Dietary fiber profile of barley flour as affected by extrusion cooking. Food Chemistry, v.77, p 3540, 2002. Disponível em: <http://www.sciencedirect.com/ science?_ob=ArticleURL\&_udi=B6T6R-45BCYDC$4 \&$ \&user $=687353 \&$ \&doc $=1 \&$ \&mt $=\&$ \&orig $=$ search \&_sort $=$ d\&_d oc anchor $=\&$ vi e w $=$ c \&_a c ct $=$ C $000037882 \&$ \& ve rs i o n $=1 \&$ \& ur l Version $=0 \&$ \& us e ri d $=687$ 353\&md5=0ef66871b8c7adf01b2781130de96183>. Acesso em 24 mar. 2009. doi:10.1016/S0308-8146(01)00318-1.

WALTER, M. Amido resistente: metodologia de quantificação e resposta biológica em ratos. 2005. 96f. Dissertação (Mestrado em Ciência e Tecnologia dos Alimentos) - Programa de Pós-graduação em Ciência e Tecnologia dos Alimentos, Universidade Federal de Santa Maria, RS.

ZELAYA, M.P. O papel da adesão e de amidos resistentes em snacks e cereais. Food ingredients, v.11, n.9, p.18-19, 2000. 